\title{
Placing wireless tablets in clinical settings for patient education EC
}

\author{
Judy C. Stribling, MA, MLS; Joshua E. Richardson, PhD, MLIS, MS
}

See end of article for authors' affiliations.

DOI: http://dx.doi.org/10.3163/1536-5050.104.2.013

Objective: The authors explored the feasibility and possible benefit of tablet-based educational materials for patients in clinic waiting areas.

Methods: We distributed eight tablets preloaded with diagnosis-relevant information in two clinic waiting areas. Patients were surveyed about satisfaction, usability, and effects on learning. Technical issues were resolved.

Results: Thirty-seven of forty patients completed the survey. On average, the patients were satisfied in all categories.

Conclusions: Placing tablet-based educational materials in clinic waiting areas is relatively easy to implement. Patients using tablets reported satisfaction across three domains: usability, education, and satisfaction.

Keywords: Audiovisual Aids, Computers, Handheld, Data Collection, Feasibility Studies, Multimedia, Patient Education as Topic, Patient Satisfaction, Aldiko, e-Reader, Nexus 7, Video Tutorial

Patients are amenable to receiving published health information that is made available to them while they are in clinic waiting areas [1-3]. Patients who make use of health education materials during their time in waiting areas are less likely to be dissatisfied with their clinical visits [4-6], which could make them more likely to seek follow-up care, keep future appointments, or comply with treatment plans [710]. Furthermore, ready access to published health information in waiting areas may mitigate the effects associated with low health literacy, such as medication non-adherence and poor clinical outcomes [11]. These findings are important in that health care organizations are under pressure to educate patients and improve overall health literacy. The findings further suggest that access to health education materials in clinical settings can improve patient satisfaction $[12,13]$.

Recent health care reforms in the United States, including the Affordable Care Act and the Health

Supplemental Table 1, Table 2, and Table 4 are available with the online version of this journal.
Information Technology for Economic and Clinical Health (HITECH) Act, mandate that health organizations use technology to promote patients' health literacy [14]. Waiting room delays can create opportunities for clinicians to provide diseasespecific health information designed to increase their patients' health literacy by making use of information technology [15-20]. Several studies have demonstrated positive results of using multimedia technology to measure the improvement of health knowledge for both low-literacy patients and patients with higher-functional health understanding [21-23].

With these challenges in mind, the authors' consumer health library set out to determine the feasibility of delivering tablet-based educational materials to patients in clinic waiting areas and to understand the effects on patient satisfaction.

\section{METHODS}

The Myra Mahon Patient Resource Center is a consumer health library affiliated with a provider 


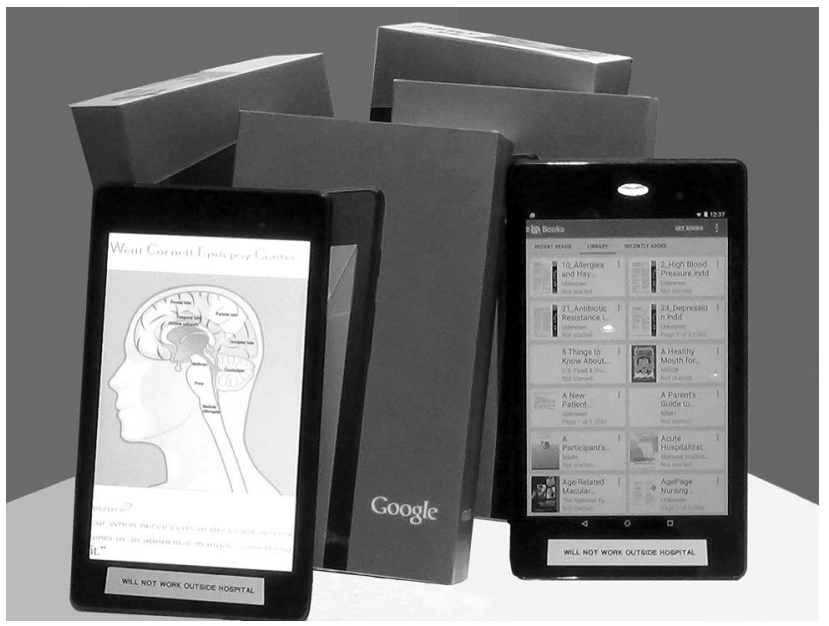

Figure 1

Nexus 7 tablets with clinical-domain-specific material

network and an academic medical center, Weill Cornell Medicine. The Institutional Review Board (IRB) at Weill Cornell Medical College approved this study.

With the support from a National Network of Libraries of Medicine, Middle Atlantic Region, Technology Improvement Award, we acquired Google Nexus 7 wireless tablets (Figure 1). The Nexus 7 was selected for its affordability and multimedia capability, including the ability to play video. All tablets were formatted to meet the institution's security and networking requirements. The first author installed an e-reader app (Aldiko ${ }^{\mathrm{TM}}$ ) on each tablet to display portable document format (PDF) files, e-books, and e-journals.

We initially recruited three clinical partners: Intervention Radiology (IR), Neurology, and Ophthalmology Clinics. They were selected due to preexisting business relationships and because each expressed interest in using information technology for patient education. However, the Ophthalmology Clinic dropped out of the project due to internal issues with scheduling.

We iteratively worked with multiple stakeholders in the IR and Neurology Clinics to develop patient workflows that integrated the tablets in waiting areas. For example, we considered the time to provide patients' access to educational materials and to complete satisfaction surveys, as well as strategies to ensure that tablets remained in waiting areas. The IR Clinic agreed to provide tablets to its patients who were waiting to receive "port placement," and the Neurology Clinic agreed to provide tablets to its patients who were receiving first-time epilepsy consults. Clinic representatives agreed to offer tablets to all patients eighteen years and older, regardless of gender, race, or ethnicity.

We collaborated with each clinic to develop and install domain-specific consumer health education content. IR developed its own sound and video PowerPoint presentation that described and demonstrated how a port is inserted into a patient to deliver chemotherapy agents. Neurology collaborated to create four electronic documents on epilepsy as well as a link to the clinic's website. Additionally, each clinic approved the first author's suggestion to include electronic materials from National Institute of Health titles.

Each clinic received 4 tablets and agreed to track how often tablets were offered to unique patients and how many unique patients accepted or declined use (Table 1, online only). Patients were asked to complete an IRB-approved, paper-based satisfaction survey after viewing any materials but before meeting with a health care provider. The survey contained questions about the tablet-based educational material that they may have viewed (Table 2, online only). Eight 5-point Likert scale questions, ranging from "very dissatisfied" to "very satisfied" pertained to satisfaction, tablet usability, and impact on learning (Table 3). Last, the IR clinic included 4 additional questions specifically related to the educational impact of the video.

The first author collected all patient survey data on a weekly basis from each department. No personal patient information or detail was recorded in the survey; therefore, Health Insurance Portability and Accountability Act (HIPAA) considerations did not apply. Study data were collected and managed in an electronic data repository (REDCap) [24]. All data were entered into REDCap during one session at the completion of the data collection period. Results were compiled and analyzed using descriptive statistics.

\section{RESULTS}

Between July 14, 2014, and August 29, 2014, staff offered tablets to 41 patients in clinic waiting areas. Forty out of 41 patients (98\%) agreed to use the tablets (Table 1, online only). One patient declined because the patient did not know how to operate the device. 


\begin{tabular}{llcc}
\multicolumn{1}{c}{ Domain } & \multicolumn{1}{c}{ Question } & $\begin{array}{c}\text { Interventional } \\
\text { Radiology* }^{*}\end{array}$ & $\begin{array}{c}\text { Neurology }^{*} \\
\text { Combined* }\end{array}$ \\
\hline Satisfaction & Quantity of information met my expectations & 4 & 4 \\
Satisfaction & Quality of information met my expectations & 4 & 4 \\
Satisfaction & I will ask to use on my next visit & 3 & 4 \\
Usability & Health information was easy to see & 4 & 4 \\
Usability & The electronic tablet was easy to use & 4 & 4 \\
Usability & Health information was easy to understand & 4 & 4 \\
Education & I feel more informed about my medical condition after using this tablet & 3 & 4 \\
\end{tabular}

Responses: $1=$ Strongly disagree, $2=$ Disagree, $3=$ Neutral, $4=$ Agree, $5=$ Strongly agree.

Table 3

Measures (median) of satisfaction, usability, and education

No patient reported using the tablet for any purpose other than viewing health-related information. More than IR patients, Neurology patients reportedly accessed online health resources beyond those that were loaded by our library (i.e., web videos, the Patient Resource Center's website [Table 2, online only]). Furthermore, no tablets were damaged, lost, or stolen; no Android operating system updates were issued or downloaded; and no patient education materials were deleted from any tablet.

Patients reported their levels of satisfaction in three domains: satisfaction, tablet usability, and perceived impact on learning (Table 3). Numeric values were assigned to patient responses. Overall, patients agreed (median score 4 ) that the tablets were usable and promoted learning, and they were satisfied with the quantity and quality of information made available. However, IR participants median scores were higher than Neurology participants on at least 1 statement in each domain. Most notably, the widest difference between the 2 clinics had to do with "feeling informed" as a result of the tabletbased materials. IR participants agreed that they were "more informed about [their] medical condition," whereas Neurology participants were "neutral" with the same statement (5 vs. 3), and 13\% of the Neurology respondents claimed they received no informational benefit from using the tablets.

All 17 IR participants were asked how much they agreed or disagreed with 4 statements having to do with aspects of understanding for port placement (Table 4, online only). Median scores of 4 and 5 demonstrate IR patients agreed to strongly agreed with statements related to satisfaction with the tablets.

\section{DISCUSSION}

Patients overall appeared to be satisfied with the quality and quantity of information delivered via the tablets and agreed they felt somewhat more educated about their particular areas of health interest. Like participants in other handheld computer studies, our patients found the Nexus tablets easy to use [25].

Our patients expressed more satisfaction with the information provided on the PowerPoint audiovideo tutorial to static PDFs presented by the tablet e-reader. Whether the information obtained from watching a video presentation was more easily retained by patients was not part of this study. Some research has suggested animations do not necessarily improve understanding of new information [26]. However, other researchers have found that, in some cases, individuals with low literacy performed better after viewing video than reading print [27, 28].

Our experiences developing the waiting room tablet program provide useful lessons for librarians and health care providers considering a similar project.

First, working with institutional IT departments is critical for success. Weaknesses in guest wireless services can lead to dropped Internet connections. Even though all educational material for this project was available without wireless connections, we hypothesized that the a tablet's lack of Internet access could lead patients to perceive it as substandard, containing less than relevant information. We made arrangements with our IT department to install Mobile Iron security software on all tablets, so that each device could access the institution's secure network. 
Second, it is critical to collaborate with clinic providers and staff to find the right fit for tablets in each clinical setting. We worked with multiple cliniclevel stakeholders to map out and agree on basic workflows for actions such as routinely handing out mobile devices to patients and allowing time for patients to access educational materials, complete the satisfaction surveys, and return the mobile devices.

Third, it is important to develop written documentation with project partners and iteratively refine that documentation throughout the span of the entire project. We continued to meet with those champions for updates and to gather feedback throughout the project. Managing relationships with clinical departments and expectations of key players in those departments is essential.

This study has several limitations. First, the participating clinics were affiliated with a provider network and academic health center and, therefore, had human and technical resources that might not be available to nonaffiliated clinics. Second, one of the practices dropped out of the study prior to data collection, thereby reducing the amount of data that we collected. Third, patients were asked to selfassess their level of being "informed," but we did not ask fact-based questions to determine if and how much knowledge they retained. Last, the surveys used in the Neurology Clinic were printed on the front and back sides of a single piece of paper. Patients might not have realized the survey continued on the other side of the paper, which could explain the number of incomplete surveys returned from the Neurology Clinic. All surveys from the IR Clinic, which had been printed on two separate pages stapled to one another, were completed.

An electronic survey published on the tablet with a direct download to the REDCap database might have resulted in a higher yield. Likewise, it is possible that additional information such as age of and level of education achieved by patient participants could be easily obtained via electronic survey. This level of information could inform further studies of health literacy and patient education.

Lessons learned from this project have been incorporated into a recently launched tablet-based patient education project in a different clinical department. The new project is designed to teach medication adherence skills to patients and to measure retention of medication advice. An electronic test is being administered to patients after viewing tablet materials. Test results and electronic survey data including patient information are automatically downloaded to a REDCap database. As personal patient information is being recorded, HIPAA considerations apply.

\section{FUNDING}

Funding was made available through a Technology Improvement Award from the National Network of Libraries of Medicine, Middle Atlantic Region. The funding source had no involvement in the submission of the paper for publication.

\section{ACKNOWLEDGMENTS}

The authors thank the clinical and administrative team members of the Departments of Interventional Radiology and Neurology without whom this project would not have been possible: Dr. Ronald Winokur, who developed the port placement tutorial and was assisted in this research by coinvestigators Jamie Stern, Eileen Chang, Morgan Leigh Hatchett, and Theresa Salerno; Dr. Douglas R. Labar, director of the Division of Clinical Neurophysiology, who agreed to provide departmental support from the Comprehensive Epilepsy Center for this study; Nurse Practitioners Fatima Belzin, Laura Ponticello, and Helene Quinn, who developed educational materials for epilepsy and first seizure disease states, and acted as coinvestigators. Loretta Merlo supplied the photograph of the Nexus 7 tablets.

\section{CONFLICTS OF INTEREST}

The authors have no conflict of interest to disclose.

\section{REFERENCES}

1. Kit Delgado M, Ginde AA, Pallin DJ, Camargo CA. Multicenter study of preferences for health education in the emergency department population. Acad Emerg Med. 2010 Jun;17(6):652-8. DOI: http://dx.doi.org/10.1111/j. 1553-2712.2010.00764.x.

2. Wei HG, Camargo CA. Patient education in the emergency department. Acad Emerg Med. 2000 Jun;7(6): 710-7. DOI: http://dx.doi.org/10.1111/j.1553-2712.2000. tb02052.x.

3. Llovera I, Ward MF, Ryan JG, LaTouche T, Sama A. A survey of the emergency department population and their interest in preventive health education. Acad Emerg 
Med. 2003 Feb;10(2):155-60. DOI: http://dx.doi.org/10. 1197/aemj.10.2.155.

4. Dansky KH, Miles J. Patient satisfaction with ambulatory healthcare services: waiting time and filling time. Hosp Health Serv Adm. 1997 Jan;42(2):165-77. 5. Oermann MH. Effects of educational intervention in waiting room on patient satisfaction. J Ambul Care Manag. 2003 Jun;26(2):150-8.

6. Moerenhout T, Borgermans L, Schol S, Vansintejan J, Van De Vijver E, Devroey D. Patient health information materials in waiting rooms of family physicians: do patients care? Patient Prefer Adherence. 2013 Jun 4;7:48997. DOI: http://dx.doi.org/10.2147/ppa.s45777.

7. Aharony L, Strasser S. Patient satisfaction: what we know about and what we still need to explore. Med Care Rev. 1993 Jan;50(1):49-79.

8. Chung K, Hamill J, Kim H, Walters M, Wilkins E. Predictors of patient satisfaction in an outpatient plastic surgery clinic. Ann Plast Surg. 1999 Jan;42(1):56-60.

9. Rosenthal GE, Shannon SE. The use of patient perceptions in the evaluation of health-care delivery systems. Med Care. 1997 Nov;35(11 suppl):NS58-NS68. 10. Ware JE, Davies AR. Behavioral consequences of consumer dissatisfaction with medical care. Eval Program Plann. 1983 Jan;6(3-4):291-7.

11. Busch EL, Martin C, DeWalt DA, Sandler RS.

Functional health literacy, chemotherapy decisions, and outcomes among a colorectal cancer cohort. Cancer Control. 2015 Jan;22(1):95-101.

12. Borusiak P, Langer T, Tibussek D, Becher T, Jenke AC, Cagnoli S, Karenfort M. YouTube as a source of information for children with paroxysmal episodes. Klin Padiatr. 2013 Dec;225(7):394-7. DOI http://dx.doi.org/10. 1055/s-0033-1353142.

13. Fat MJL, Doja A, Barrowman N, Sell E. YouTube videos as a teaching tool and patient resource for infantile spasms. J Child Neurol. 2011 Jul;26(7):804-9. DOI http:// dx.doi.org/10.1177/0883073811402345.

14. Bauer AM, Thielke SM, Katon W, Unützer J, Areán P. Aligning health information technologies with effective service delivery models to improve chronic disease care. Prev Med. 2014 Sep;66:167-72. DOI http://dx.doi.org/10. 1016/j.ypmed.2014.06.017.

15. Beck RJ, Ellis LB, Scott DM, Raines JR, Hakanson N. Microcomputer as patient educator. Am J Hosp Pharm. 1982 Dec;39(12):2105-8.

16. Elangovan S, Kallail KJ, Vargo G. Improving pneumococcal vaccination rates in an elderly population by patient education in an outpatient clinic. J Am Board Fam Pract. 1996 Dec;9(6):411-3.

17. Lledó R1, Herver P, García A, Güell J, Setoain J, Asenjo MA. Information as a fundamental attribute among outpatients attending the nuclear medicine service of a university hospital. Nucl Med Commun. 1995 Feb 1;16(2): 76-83.
18. McCarthy DM, Engel KG, Buckley BA, Huang A, Acosta F, Stancati J, Schmidt MJ, Adams JG, Cameron KA. Talk-time in the emergency department: duration of patient-provider conversations during an emergency department visit. J Emerg Med. 2014 Nov;47(5):513-9. DOI: http://dx.doi.org/10.1016/j.jemermed.2014.06.056. 19. Papa L, Seaberg DC, Rees E, Ferguson K, Stair R, Goldfeder B, Meurer D. Does a waiting room video about what to expect during an emergency department visit improve patient satisfaction? CJEM. 2008 Jul;10(4):347-54. 20. Seibert T, Veazey K, Leccese P, Druck J. What do patients want? survey of patient desires for education in an urban university hospital. West J Emerg Med. 2014 Nov;15(7):764-9. DOI: http://dx.doi.org/10.5811/westjem. 2014.9.20674.

21. Kandula NR, Nsiah-Kumi PA, Makoul G, Sager J, Zei CP, Glass S, Stephens Q, Baker DA. The relationship between health literacy and knowledge improvement after a multimedia type 2 diabetes education program. Patient Educ Couns. 2009 Jun;75(3):321-7. DOI: http://dx. doi.org/10.1016/j.pec.2009.04.001.

22. Bryant MD, Schoenberg ED, Johnson TV, Goodman M, Owen-Smith A, Master VA. Multimedia version of a standard medical questionnaire improves patient understanding across all literacy levels. J Urol. 2009 Sep 1; 182(3):1120-5. DOI: http://dx.doi.org/10.1016/j.juro.2009. 05.027 .

23. Wang DS, Jani AB, Sesay M, Tai CG, Lee DK, Echt KV, Goodman MG, Kilbridge KE, Master VA. Video-based educational tool improves patient comprehension of common prostate health terminology. Cancer. 2015 Mar 1; 121(5):733-40. DOI: http://dx.doi.org/10.1002/cncr.29101.

24. Harris PA, Taylor R, Thielke R, Payne J, Gonzalez N, Conde JG. Research electronic data capture (REDCap) - a metadata-driven methodology and workflow process for providing translational research informatics support. J Biomed Inform. 2009 Apr;42(2):377-81. DOI: http://dx. doi.org/10.1016/j.jbi.2008.08.010.

25. Main DS. Exploring patient reactions to pen-tablet computers: a report from CaReNet. Annals Fam Med. 2004 Sep 1;2(5):421-4.

26. Mayer RE, Hegarty M, Mayer S, Campbell J. When static media promote active learning: annotated illustrations versus narrated animations in multimedia instruction. J Exp Psychol Appl. 2005 Dec;11(4):256-65. 27. Wilson EAH, Park DC, Curtis LM, Cameron KA, Clayman ML, Makoul G, Vom Eigen K, Wolf MS. Media and memory: the efficacy of video and print materials for promoting patient education about asthma. Patient Educ Couns. 2010 Sep;80(3):393-8.

28. Murphy P, Chesson A, Walker L, Arnold C, Chesson L. Comparing the effectiveness of video and written material for improving knowledge among sleep disorders clinic patients with limited literacy skills. South Med J. 2000;93(3):297-304. 


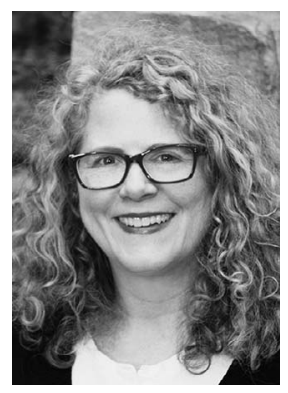

AUTHORS' AFFILIATIONS

Library, Weill Cornell Medicine, 1305 York Avenue, New York, NY 10065; Joshua E. Richardson, PhD,

Judy C. Stribling, MA, MLS MLIS, MS, jrichardson@rti.org, Health Information (corresponding a uthor), Technology (IT) Researcher, Center for the Advancejcs2002@med.cornell.edu, Assis- ment of Health IT at RTI International, Chicago, IL tant Director, Clinical Services, 60606

Myra Mahon Patient Resource

Center and Samuel J. Wood Received September 2015; accepted November 2015 